\title{
Temperate Agroforestry: How Forest Garden Systems Combined with People-Based Ethics Can Transform Culture
}

\author{
Paul Wartman *, Rene Van Acker and Ralph C. Martin \\ Department of Plant Agriculture, University of Guelph, Guelph, ON N1G 2W1, Canada; \\ vanacker@uoguelph.ca (R.V.A.); rcmartin@uoguelph.ca (R.C.M.) \\ * Correspondence: pwartman@alumni.uoguelph.ca
}

Received: 30 May 2018; Accepted: 27 June 2018; Published: 29 June 2018

\begin{abstract}
How can transforming monocultures to diverse polycultures address and solve the intersecting issues of our food system? This literature review offers community resources, practical examples, and academic research to support the shift away from monocultures, and the broader social contexts that encourage them, and towards food systems as part of cultures that prioritize people, water, and the land. Forest garden systems are presented as a temperate agroforestry-based food system design which make use of multiple perennial plants to meet human needs for food, medicine, fuel, and more while regenerating the environment in which they grow. There is a lack of peer-reviewed research in temperate forest garden systems, but it is gaining momentum alongside an increasing application in non-academic contexts. Combined with cultural principles that prioritize people, the land, and water over profits, forest garden systems are proposed as a pathway for meeting local community's needs and environmental regeneration.
\end{abstract}

Keywords: forest garden; temperate agroforestry; woody perennial polyculture; perennial agriculture; Indigenous; community; permaculture

\section{Introduction}

In temperate regions of Turtle Island (known to many as the continent of North America), some areas such as Southern Ontario have largely been transformed from forest, wetland, and grassland to urban development and monoculture agriculture [1]. Consequences of such a large-scale change in landscape include the interconnected losses of decreased biodiversity, soil erosion, increased contributions to climate change, water contamination, hydrological imbalances, and dependence on fossil fuelled mechanization for management $[2,3]$. The degrading impact on these ecosystems is inherently connected to all peoples' health, and contributes to ethnocide of the local Indigenous communities whose culture is this land and water. The shift away from monoculture agricultural practices and the resurgence of land-based, Indigenous systems is occurring. Forest garden systems (FGSs) present an opportunity to grow for human needs using practices that are environmentally regenerative, regionally appropriate to the ecology, and resilient to pests, diseases, drought, and economic changes. FGSs are described as a diverse group of plants, mostly perennial, which provide multiple services to help humans meet their needs locally for food, medicine, shelter, recreation, fibres, dyes, fodder for animals, fuel, and more [4]. Land stewards and growers (e.g., farmers, ranchers, nursery people, gardeners, etc.) are increasingly recognizing that growing with diverse perennial plants can protect and regenerate the land. However, long-term research on diverse perennial systems is underdeveloped, as are the policies and funding for it. In respectful collaboration, settler and Indigenous science systems can support the growth of skills to work with perennial plants and to share 
the principles necessary to create food systems centered upon a culture that cares about people and recognizes its inextricable connection to the land and the water.

Within this paper, I will use the word "Indigenous" to describe humans whose ancestral home is Turtle Island. The word "settler" is used to describe any human currently living on Turtle Island post European-contact whose ancestry is from another part of the Earth (i.e., European-colonizers, settlers, immigrants, refugees, and new comers of any means).

The purpose of this paper is to introduce temperate-climate FGSs as a practice connected to agroforestry with suggested cultural frameworks for developing long-term, community-based FGS trials. We will briefly review the impacts of deforestation by monoculture agriculture (focus on S. Ontario) and how communities are re-growing transformative food systems, along with academic support.

\section{Background}

FGSs are not new; rather they are traditional to communities who evolved in forest ecosystems all over the world. In the tropics, FGSs are characterized as homegardens or agroforests (i.e., a cross between low-managed forests and specialized tree crop plantations) [5]. In temperate regions they are related to agroforestry, woody perennial polycultures, multifunctional woody polycultures, and forests. They were and are protected, established, and maintained by peoples indigenous to their area [5]. FGSs are designed using the knowledge of local communities to achieve goals of conserving the plants, as well as land and water, on which their lives depend [5]. In temperate regions, forest ecosystems have been and still are an integral component of human livelihoods and they yield multiple uses for the local and global economies [6].

FGSs expand the present-day application of agroforestry to include land-use and life systems designed primarily with diverse, multi-layered perennials and self-sowing annuals that mimic the structure of natural forest, woodland, and savannah ecosystems. The goals of FGSs are to prioritize local needs of humans by achieving a state of abundant diverse yields, self-fertilization, self-maintenance, and self-renewal, as well as healing the land from past and present degradation $[4,5,7]$. In combination with design frameworks (i.e., cultural principles) that prioritize people, the land, and the water, FGSs have the potential to rehabilitate food systems and grow communities that thrive alongside the ecologies they are in relationship with.

Agroforestry practices support ecosystem services, provide environmental benefits, and diversify economic opportunities as a multi-functional landscape [8]. Agroforestry has been defined as a land-use system in which trees and/or shrubs are introduced into agricultural cropping and livestock systems or where crops are planted into forest systems [8]. The science on agroforestry has provided a plethora of research on perennial-based food systems (Table 1) and has demonstrated concrete contributions from perennial plants. In addition to the yielding of tangible items for human use (e.g., fruits, nuts, medicine, flowers, fibres, lumber, fuel), perennial plants contribute to ecosystem services in multiple ways including; carbon sequestration, nutrient accumulation, water storage and filtration, production of food for non-human life, habitat creation and shelter, and other mutually beneficial interdependencies [6,8-10]. However, in temperate research and application these practices have predominantly been applied to agricultural systems that are mono-cropping, highly mechanized, pesticide- and fertilizer-dependent, instead of transforming it to highly diversified interdependent systems that utilize human-scale appropriate technology and ecological practices [10].

Despite many years of practice in North America and Europe prior to the "Green Revolution" and 30+ years of recent research, applications of agroforestry practices, such as FGSs, are slow to regrow. Two larger societal contexts help to explain the slow relearning. One is colonial policies enacting ethnocide, resulting in fewer people with relationships to local plants and ecologies, as well as ongoing disconnection from and destruction of local ecologies [11]. The second is intersecting capitalist approaches of larger-scale production of monocultures for export markets, which is the opposite of supporting home gardens and small-scale growers as recommended by the UN's Special Rapporteur 
On the Right to Food [12]. Additional grower-based reasons include: lack of research demonstrating the yield potentials of many perennials, especially within a polyculture and with multiple vertical layers; how to use and or market multiple plants; uncertainty around the design process with diverse perennial plants and site-specificity with few long term examples to model after, especially on larger area scale. Farming and forestry practices, policies, and markets have been separated from each other making it more complicated for growers [7]. Also, some growers perceive the costs for establishing perennials, and the necessary skill-base to manage them, as a risk for profitability with agroforestry yields [13].

Table 1. Major agroforestry practices and descriptions (compiled by Nerlich et al. [8]).

\begin{tabular}{cl}
\hline Agroforestry Practice & \multicolumn{1}{c}{ Description } \\
\hline Silvoarable systems & $\begin{array}{l}\text { Trees are planted in single or multiple rows with arable or horticultural crops } \\
\text { between the rows }\end{array}$ \\
\hline Silvopastoral systems & $\begin{array}{l}\text { Trees are combined with forage and livestock production including high } \\
\text { (forest or woodland grazing) and low density (open forest trees) stands }\end{array}$ \\
\hline Orchard intercropping & $\begin{array}{l}\text { Fruit tree systems on arable land or grassland mixed with grazing animals } \\
\text { (special agroforestry system) }\end{array}$ \\
\hline Forest farming & $\begin{array}{l}\text { Utilizing forested areas for producing or harvesting natural or cultivated } \\
\text { specialty crops for medical, ornamental, or culinary uses }\end{array}$ \\
\hline Riparian buffer strips & $\begin{array}{l}\text { Perennial vegetation (grass, shrubs, trees) are planted in strips between arable } \\
\text { land or pastures to enhance and protect aquatic resources (streams, lakes) } \\
\text { from negative effects of agricultural practices }\end{array}$ \\
\hline Windbreaks & $\begin{array}{l}\text { Rows of trees are planted around farms and fields to protect crops, animals } \\
\text { and soil from wind. }\end{array}$ \\
\hline
\end{tabular}

In this review of the literature on and relevant to FGSs, we share four sections. The first acknowledges the history of the land in Southern Ontario as an example of a temperate region that once was primarily forest and could be returned to a forest-based ecosystem to provide for peoples' needs. Second, we reference frameworks for food system design (i.e., cultural principles) that guide growers' actions in relation to local ecologies. Third, a sampling of non-academic communities and people modelling temperate FGSs will be provided, and, lastly, we present how academic institutions are developing practices to support the growth of FGSs through community-based research.

\section{Example Land Acknowledgement of Southern Ontario}

The temperate regions of the world have different conditions that support diverse ranges of ecosystems. For example, Canada, which is a colonized portion of Turtle Island and traditional territory to hundreds of unique Indigenous-First Nations, Metis, and Inuit-communities, has temperate regions that are approximately $50 \%$ forest cover, containing, among others, the deciduous forest biome [14]. Southern Ontario's landscape, which is traditional territory and home to over 133 First Nations and Metis communities, is made up of the mixed-wood plains ecozone in the north and is the Carolinian ecozone in the south, which is the most tree species-diverse zone in Canada, with more than 1600 plant species [14]. These lands are traditional territory to the many First Nation communities of the Anishinabek, Haudenosauneega, Odawa, and Huron-Wendat Nations [15-19].

We reference the Indigenous communities of this land because they were on this land, interacting within the ecosystems, long before any of the referenced academic studies. Despite this long term relationship and knowledge, the great potential for cooperation between the academic communities and the Indigenous communities is largely disconnected and often suppressed. As we develop sustainable solutions to chronic issues in our food systems, it seems vital that we make space for local Indigenous communities. They have the longest relationships with not only the base of our shared solution-local ecosystems—-but also with the intersecting societal patterns that maintain the 
issues-imperialism, capitalism, white (i.e., European ancestry) privilege, and patriarchy. The intention to be aware of these intersecting issues, and how they are manifested, aids in contributing to solutions and may mitigate the risks of perpetuating the problems we hope to help solve. As Leanne R. Simpson states: "Unless academics, researchers, institutions, and Indigenous nations are prepared to name the forces that have threatened Indigenous knowledge and threatened Indigenous Knowledge holders and challenge the colonizing forces currently within the academy, our attempts to use Indigenous knowledge as a tool for decolonization will certainly fail [20]". As authors, we are self-critical when making space for Indigenous perspectives because we are highly influenced by our societal culture and by a University of Guelph agricultural mandate that advances agricultural research and education: on Treaty 3 land, which has not been honoured by the current settler occupants or "Her Majesty the Queen" of England; is funded in part by many of the largest multinational and national corporations; and, has older men with European ancestry in the highest positions of decision making power [21-23]. Sharing academic realities exemplifies relationships to the societal patterns mentioned above. Indigenous cultures-languages, traditions, relationships with land, etc.-have assisted settlers to survive in this landscape in the past and, if truth and reconciliation by settlers is honoured, may assist in the creation of food systems that benefit all people living on this land, now and in the future. Relevant Indigenous knowledge will probably be left out of this review due to factors including our lack of such knowledge, Canadian policies that caused intentional destruction of their cultures (e.g., Indian Act), and the general lack of relationship with Indigenous communities in the agricultural academic sphere [11]. This concern stems from an intention to be in relationship with them so that their knowledge is respected, not co-opted or separated out of the context of their knowledge systems [20]. We continue to make efforts to include Indigenous sources, and encourage all academics to creatively work with them, recognizing that the settler-created peer reviewed academic system currently has many barriers for their knowledge and cultural practices to be included (e.g., many Indigenous communities have no written language and traditionally communicate orally in languages that are not English, which is predominantly rejected in peer-reviewed science) $[20,24]$. Acknowledging all of this as a cultural pattern that can be changed is one step in de-colonizing academic research and it presents the opportunity to continue learning with the people who have the longest relationships with the land we are growing with.

Butt et al. described the 19th century land cover in S. Ontario. It included large areas of forest species including maple (Acer spp. L.) and beech (Fagus grandifoloia L.) which covered most of S. Ontario, with larger patches of black ash (Fraxinus nigra Marshall) swamps, oak (Quercus spp. L.) forest, and interspersed patches of hemlock (Tsuga spp. Carriere), willow (Salix spp. L), tamarack (Larix spp. (Du Roi) K. Koch), chestnut (Castanea spp. L.), birch (Betula spp. L.), cedar (Cedrus spp. L.), spruce (Picea spp. Mill.), pine (Pinus spp. L.), poplar (Populus spp. L.), elm (Ulmus spp. L.), and briar thickets [25]. These forest type classifications are indicative of the major canopy species and contain within them multiple understory species of plants, animals, and microorganisms. This plant species composition is a result of long-term-hundreds of thousands of years-environmental pressure from glacier-formed topography, climate, and soil parent materials [26]. Within these larger scale contexts, ecological succession is perpetuated by ongoing shorter-term relationships, such as plant-affected soil changes (e.g., decrease in $\mathrm{pH}$ or increase in nutrients), alongside complex symbiotic relationships among diverse biotic and abiotic elements. Ecological succession is the series of biological stages and transitions over a relatively short period of time that occurs after disturbance (e.g., agricultural cultivation, forest fires, extreme weather, and biological control including large mammal browsing, insect herbivory, and disease) [26]. These internal mechanisms contribute to ecosystem growth and resiliency, which is the capacity of a system to recover to a pre-existing state after disturbance [26]. For example, when soil is ploughed in S. Ontario, certain plants will quickly grow to cover the soil and eventually, if there is no further disturbance, woody perennials will start to grow and form a forest.

Prior to European contact, colonization, and settlement in the 18th and 19th centuries, S. Ontario had over $80 \%$ forest cover [25]. According to settler records, before and during European colonization 
some Indigenous communities may have used, and may continue to use, fire for living space and trail maintenance, to prepare agricultural land, and to care for animal habitat. Indigenous communities allowed the majority of forest and wetlands to remain intact for use in their interconnected physical, cultural, spiritual, and material activities, as well as preserving the intrinsic services of the natural environment with which they, and all humans who occupy this land, are interdependent $[5,6,25]$. Compared to the minimal disturbance pre-colonization, there is now only approximately $10 \%$ forest cover remaining in S. Ontario [14]. Development of settler agriculture and urbanization removed perennial vegetation from $70 \%$ of an entire landscape in under three hundred years $[1,25]$. Agriculture has transformed ecosystems in S. Ontario from a state of high species and structural diversity to a state of very low species diversity and structure [27]. This shift in ecological state has coincided with the removal of and harm to Indigenous peoples who still occupy this land; has resulted in polluted ecosystems; and, created agricultural lands that are heavily dependent on the use of external inputs including pesticides and fertilizers [20,28-30].

While the above example is focused on S. Ontario, this context of imperialism and associated environmental destruction is widespread throughout most of Turtle Island and many other parts of the world.

In temperate regions of Turtle Island there is increasing recognition by settlers that forests are integral to the lives of humans and non-human beings. This knowledge, and the science within their relationships, is inherent in many surviving Indigenous cultures. Agroforestry and other models of agriculture, such as permaculture and agroecology, are increasingly acknowledging that regional Indigenous peoples and their cultures are keystones to developing life systems that meet peoples' needs while caring for people and land. This is paramount to acknowledge, respect, and align with if food systems want to intersect with peace and justice, as well as truly achieving food security and sovereignty [12].

Stating the historical patterns of relationships between people and the land offers truth to reflect on. Looking back on how we have worked with the land to meet our human needs can hopefully demonstrate how we must shift our practices so that degradation is interrupted and healing-reconciliation—can begin alongside a balanced, fair growth.

\section{Design Frameworks to Guide Forest Garden Systems}

Many people continue to comment on and criticize the history of agriculture post "Green Revolution" and how the above-mentioned major land disturbances have led to extreme ecological shifts and in some cases societal catastrophe including the continual destruction of Indigenous cultures $[3,12,29,31,32]$. These same people and organizations have maintained, revived, sustained, and grown holistic food system frameworks, offering models that align human needs with flows of local ecologies.

The Working Group on Indigenous Food Sovereignty, led by Dawn Morrison, was formed in 2006 with the understanding that Indigenous communities have developed locally distinct and long standing strategies for harvesting food [33]. They represent the voices of Indigenous harvesters (i.e., hunters, fishers, gatherers), farmers, gardeners, academics, and community members within the food security movement. Located primarily in the major regions around the province of B.C., they organize meetings, attend conferences, and work with non-Indigenous stakeholders to increase awareness and action on Indigenous food sovereignty. " . . the trends occurring amongst Indigenous peoples are the beginnings of a new Indigenous food sovereignty. By establishing their own projects under their own leadership, Indigenous peoples are determining what should be grown, cooked, taught, and shared ... Indigenous stewardship practices and traditional knowledge of the land may help the general Canadian society appreciate its responsibilities to the land." [31]. To assist the achievement of these goals, the Food Sovereignty Assessment Tool created by Alicia Bell-Sheeter with the Native Agriculture and Food Systems Initiative, First Nations Development Institute can be implemented. 
Bill Mollison co-founded the permaculture movement with David Holmgren. They provide historical reports on the importance of observing the structural patterns of local natural systems in order to design regenerative, place-based food systems and cultures. He also critiqued modern agricultural dependencies on fossil fuels and the capitalist system, pointing out the destructiveness and fragility of it. His methods are inspired by indigenous ecologies, traditional techniques, and modern issues, and address the highly nonlinear dynamics of complex landscapes [34].

Agroecology is described by Tomich et al. as "the integrative study of the ecology of the entire food system, encompassing ecological, economic and social dimensions", and provides a framework for the design and management of low input, ecological service-based food systems [3].

If we, as a society, hope to achieve the goals of feeding, sheltering, and keeping our communities healthy, critical reflection of the existing popular frameworks that inform our current practices is necessary. The current capitalist framework encourages profiting from increasing costs of basic needs while largely ignoring, or externalizing, the impacts on the environment and people. The frameworks mentioned above offer alternatives, but in order to make change, they must be shared and applied. If these alternatives are applied, food systems could be designed to quite literally transform the world, as monoculture agriculture has. Learning the guiding principles (Table 2) of these frameworks, in addition to reflecting on how we might respectfully adapt them, may help us to better interact with complex local ecosystems. If designed through these frameworks, FGSs have the potential to produce for the needs of human communities while protecting the land and water, as well as dismantling the intersecting issues that threaten human existence.

Table 2. Traditional Indigenous maxims, Permaculture ethics, and Agroecological principles for the design of biodiverse, energy efficient, resource-conserving and resilient food systems

\begin{tabular}{ll}
\hline Source & \multicolumn{1}{c}{ Principles } \\
\hline - The Earth is Our Mother \\
-
\end{tabular}

\begin{tabular}{|c|c|}
\hline Tomich et al., 2011 [3] & $\begin{array}{l}\text { - Enhance the recycling of biomass, with a view to optimizing organic } \\
\text { matter decomposition and nutrient cycling over time. } \\
\text { - Strengthen the "immune system" of agricultural systems through } \\
\text { enhancement of functional biodiversity-natural enemies, antagonists, etc. } \\
\text { Provide the most favourable soil conditions for plant growth, particularly } \\
\text { by managing organic matter and by enhancing soil biological activity. } \\
\text { - Minimize losses of energy, water, nutrients and genetic resources by } \\
\text { enhancing conservation and regeneration of soil and water resources } \\
\text { and agrobiodiversity. } \\
\text { - Diversify species and genetic resources in the agroecosystem over time } \\
\text { and space at the field and landscape level. } \\
\text { Enhance beneficial biological interaction and synergies among the } \\
\text { components of agrobiodiversity, thereby promoting key ecological } \\
\text { processes and services. }\end{array}$ \\
\hline Mollison 1989 [35] & $\begin{array}{ll}\text { - } & \text { Care of Earth } \\
\text { - } & \text { Care of People } \\
\text { - } & \text { Regulate our use and redistribute surplus }\end{array}$ \\
\hline
\end{tabular}




\section{History of Forest Garden Systems and Communities of Practice}

The majority of temperate FGS knowledge, practices, and resources are not included within the academically peer-reviewed system, which contrasts with the availability of studies and practices in tropical regions [5]. We include the following to recognize that multiple individuals, communities, and organizations are implementing FGSs primarily outside of academia and to share resources on how and why they are creating solutions to their needs within their local context. These sources are derived from reading the cited texts, online articles, in-person visits, and conferences. They are important because there is an opportunity for academics to recognize that communities, as opposed to larger corporations, initiate solutions to their local issues and to support the communities who are practicing these systems.

It is important to acknowledge, again, that many Indigenous communities have been shaping ecosystems for thousands of years before settler science existed on this land, before FGS was even a term, and that our use of this term does not erase their practices. Hopefully FGS research aligns with Indigenous practices if and when appropriate.

\subsection{Forest Gardening Communities and Resources in the United Kingdom and United States of America}

The first known temperate-climate FGS to be documented is Robert Hart's garden in England [4]. It was planted in 1979, has an area of $3200 \mathrm{sq} \mathrm{ft}$, is in the USDA hardiness zone 8, and was consciously created as a perennial, self-sufficient home garden to serve his basic needs. Much like multi-strata forest gardens in the tropics his garden has three intentionally designed vertical layers, consisting of canopy trees, including plums (Prunus spp. L.), apples (Malus spp. Mill.), pears (Pyrus spp. L.), elder (Sambucus nirgra L.), Trust. He formed a participatory Forest Garden Network with 1100 members so that elm, ash, and hawthorn (Crataegus spp. Tourn. ex L.), understory shrubs, including Ribes spp. L., Rubus spp. L., hazelnuts (Corylus avellana L.), roses (Rosa spp. L.), and Siberian pea shrubs (Caragana arborescens Lam.), and over 25 herbaceous species, including chives (Allium schoenoprasum L.), comfrey (Symphytum officinale L.), good King Henry (Chenopodium bonus-henricus L.), mints (Mentha spp. L.), grasses, and nettles (Urtica dioica L.). Jacke and Toensmeier [4] share other structural layers, which contain within them diverse functional roles, including the following from tallest to shortest: canopy/tall trees, sub-canopy/large shrubs, shrubs, herbaceous plants, ground covers/creepers, underground/root zone-occupying plants, mushrooms, and vines.

Inspired by the texts Forest Gardening [36] and Tree Crops: A Permanent Agriculture [37], many people continue to expand both in scale and capacity upon Hart's FGS model.

Martin Crawford is the Trust Director of the Agroforestry Research practitioners could learn about and share their research on perennial polycultures [38]. The Trust has published a textbook, "Creating a Forest Garden" [39], publishes Agroforestry News [40] and produces a quarterly newsletter that focuses on temperate plant projects. In addition, a 10 acre Forest Garden Project was created in 1994. It demonstrates multi-strata plants (140 different species) that coexist, producing fruits, nuts, edible leaves, spices, medicinal plants, poles, fibres, basketry materials, honey, fuelwood, fodder, mulches, game, mushrooms, and sap products.

Eric Toensmeier is an author of multiple texts on perennial plants, is a co-author with Dave Jacke of Edible Forest Gardens Vol I \& II [4], and is a researcher and lecturer of permaculture and "carbon farming" across the globe. These texts present many non peer-reviewed case studies that offer comprehensive insight into the theory and practice of FGSs, as well as processes for designing FGSs of different scales.

"Plants For A Future" is a 20 year old charity that focuses on researching and openly sharing information on ecologically sustainable food production systems and plants, specifically "woodland gardening". They partner with the Permaculture International Research Network and the Permaculture Association of Britain to work toward achieving their goals of: (1) establishing baseline data for permaculture research with a focus on temperate-climate perennial polycultures; (2) assessing permaculture research for future directions; and (3) engaging people to get involved in FGSs. 
Tomas Remiarz [41] completed a survey of 114 temperate-climate FGSs around the world with 46 and 27 of those gardens being in the UK and the USA, respectively. Garden sizes ranged from a few square meters to 30 hectares (the majority were under 1 ha), and forest garden uses varied from private gardens $(59 \%)$, to community gardens $(24 \%)$, to commercial farms $(15 \%)$. The latter were not primarily based on sales of produce but rather on education and tours. The earliest of these FGSs were started in the 1980s but the majority were established after 2000. The results of this survey provide baseline numbers and guiding questions that aid in the direction of a 10-year food forest research project. The project is in its fourth year and consists of 10 practitioner participants who are practicing food forest systems on 1 hectare or less. The focus of the study is to determine (1) the ratio between energy input and yields regarding economic, social, and biodiversity metrics; (2) whether FGSs are economically viable; and (3) the application of FGSs in urban design [41].

Commercial operations, such as the New Forest Farm and Badgersett Research Corporation, located in Wisconsin (Ho-Chunk, Menominee, and Miami territory) and Minnesota (Anishinabek territory) respectively, are supporting growers all over Turtle Island to transition from small, homestead or private gardens, to larger scale FGSs (e.g., 110 acres), and from annual staple crops (e.g., corn) to woody perennial staple crops, such as hazelnuts, walnuts, and pecans [42,43]. Both offer resources on design, ecology, and layout of woody perennial systems for production of marketable items.

\subsection{Community Forest Gardens in Ontario, Canada}

Gregg Root and the Saugeen First Nation community east of Lake Huron have grown a forest garden for the purposes of community and greater public education, food, and medicine. The garden has over 30 species of trees, shrubs, and herbs, many of which are native to the area and of cultural significance [44].

In London, Ontario (Anishinabek and Haudenosauneega territory), Jessica Robertson from Wild Craft Permaculture [45] has been involved in a food forest project called Carolinian Food Forest since 2012. The goals are to return public land into a forest that provides long-term food for the surrounding community by growing native plants. She is also working with members of the Chippewas of the Thames First Nation and Fanshawe College to grow a 5-acre food forest for The Chippewa Sustainable Living Project [46]. Just outside of London is The Living Centre where courses for hands-on experience in growing forest gardens are offered. The facilitator and land steward, Shantree, states online: "It is about returning to a place of honouring our relationship and connection to Nature, of sacred partnership with the living planet and reinventing whole connected thriving ecosystems that sustain and regenerate all life [47]".

In Guelph, Ontario, (Anishinabek and Haudenosauneega territory) the City of Guelph corporation and community members worked together to plant over 500 trees, shrubs, vines, and other perennials to form their first food forest on public property. The goals of the FGS are to "plan, design, implement, and use a demonstration food forest for education purposes on topics of food security, urban green space design, water management, pollinator habitat and natural heritage [48]".

These are some examples of ranging sizes and applications of FGSs that can inspire and be modelled for academic and non-academic purposes. Many of these projects are community-based, charities or non-profits, as opposed to large for-profit corporations, and are working within their local context to meet the needs of their communities. Few are beginning to cooperate with local First Nation peoples to learn and grow together. They may benefit from supports that the academic community can offer, such as complementary measurement tools, sharing of funds, labour, and work tools, and amplification of results and future needs.

\section{Present Academic Contributions to Forest Garden Systems}

Historical and present day practice of settler-agriculture on Turtle Island, including academic research, has been heavily directed and informed by colonial government policies [49-52]. The long-term results are often in direct opposition with local community needs, soil quality, and 
water quality. Due to the reality of most academic institutions and their funding relationships with larger corporations and colonial governments, it is critical to keep the design frameworks mentioned above at the forefront of collaborative research with communities. Also, for all of the reasons stated previously, it is important to address imperialism by actively making space for Indigenous food sovereignty perspectives and prioritize their contributions while designing solutions to complex societal problems [20].

FGSs and frameworks such as permaculture are catching the interests of academics in Turtle Island due in part from the success of perennial-based growers such as Jessica Robertson with the Chippewas of the Thames First Nation, Robert Hart, J. Russel Smith, and Mark Shepard. The following situations are examples of how academics are working with individual and groups of growers to develop, implement, track, review, and amplify the growth of forest garden systems.

The newest quantitative academic research on temperate forest garden systems is emerging from the research team led by Dr. Sarah Taylor Lovell from the University of Illinois, Urbana-Champaign, who is researching multiple factors in Oak savanna-based woody perennial polycultures [53]. She is developing a research infrastructure which consists of 5 acres of intercropped chestnuts (Castanea spp.), hazelnuts, apples, grapes (Vitis vinifera L.), currants, raspberries, with alleys planted to perennial pasture mix of grasses and clover for potential grazing by livestock [53]. Factors measured in the study include aspects of biogeochemistry (e.g., carbon fluxes, nitrous oxide emissions, nitrate leaching, self-fertility, water use efficiency, drought tolerance, runoff and erosion), ecology (e.g., biodiversity, phenology, resiliency), agronomy (e.g., establishment, maintenance, harvesting and processing), and economics (e.g., diverse and total yield, nutritional composition, economic modelling, and inputs). In addition to the quantitative research, the yields of the plot-food, learning, and carbon sequestration-benefit the campus and greater communities. This is novel, comprehensive, and complex research that is being completed that can be mimicked and scaled by research centres in temperate regions globally.

Dr. Taylor Lovell is also partnering with the Savanna Institute, which has created a formal case study that involves 7 commercial-scale farms in Wisconsin and Illinois (Haudenosaunee, Miami, Sauk, and Meskwaki territory) where they are tracking ecological, economic, and social impacts during transition from conventional farming to restorative agricultural practices, which includes FGSs and integrative design [54]. Research reports are available on the topics of: agroforestry performance, pests and pollinators; silvopasture establishment and tree protection; long-term leases for agroforestry; currant performance trials; serviceberry performance trials; carbon sequestration on agroforestry farms; and, the fruit and nut compass, which is a quantitative tool to support fruit, nut, and berry growers with diversified operations to make decisions about integrated cropping management and marketing. The Savanna Institute also provides educational trainings (in-person and online), resources for land access and agroforestry practices, a community newsletter, and generally setting up a learning community to increase awareness and practice of agroforestry. These documented models of transition from "conventional" to "restorative" practices are pivotal to the broader application of these practices in the farming community, especially on a commercial scale. The strategy to include farmers and growers in all aspects of research in addition to the educational community networking that's being created is a fantastic model to replicate if community-involved research is a goal $[54,55]$.

To aid in the formation of long-term field trials for woody perennial polyculture systems, Lovell et al. [7] have developed research design processes that consider the respective needs of farmers and research facilities. It comprehensively lays out components of experimental designs (tools for diverse perennial planning, issues to consider, next steps needed, etc.) and shares two long-term case studies (operating at Restinclieres Estate Farm in France and Horticulture and Agroforestry Research Center, University of Missouri Center for Agroforestry in the US) with specific trials to demonstrate the potential, as well as the set up, of these trials. Multiple references are provided in order to replicate the metrics for evaluation and methodologies for quantification of ecosystem services, such as production, plant biodiversity, water use dynamics, nutrients, microclimates, carbon 
sequestration and more. Included are examples of how trial results impacted national and international policy (e.g., agroforestry recognized as a standard agricultural management and included in the Common Agriculture Payments scheme in France). They also share how they apply the lessons learned on their new project "Agroforestry for food", which is a new long-term field experiment at the University of Illinois. Agroforestry for food is a 12-hectare site that includes 28 large plots to compare 7 treatments ranging from a corn-soybean rotation to monoculture trees to plots of increasingly complex multi-species perennials. It hopes to intentionally address the themes of food security, climate change, multifunctionality, and "applied solutions" which develop practical options for growers. Their conclusion states that reproductions of these studies on larger scales are needed to support broad adoption of these systems by growers, as well as that the development infrastructure of agroforestry is growing.

The past three examples with Lovell et al. [7] focus on growing multifunctional woody perennial systems to meet multiple human needs on the local level while addressing large societal issues (e.g., climate change and biodiversity loss). There is a major focus on commercialization and production capacity, which again is important to reflect on to understand who these systems are growing for-community needs and export trade goals are important to consider. As it currently is, there is no mention of the societal systems these production agroforestry systems are complicit in-imperialism and capitalism - and so the potential of a transformative food system culture may be reduced. Many comprehensive and tangible models are provided which is extraordinarily helpful for other regions to mimic. However, it is critical to note that future work could benefit greatly from adopting an Indigenous solidarity lens in addition to some of the people-and land-based frameworks shared previously in this paper.

Informed by Lovell et al. [7], a study in Sweden followed a group of 12 participant growers as they established (i.e., first four years of growth) edible forest gardens $\left(60 \mathrm{~m}^{2}\right.$ in size) on farms ranging in size from 3 to 200 hectares [56]. The FGSs were designed with the same species composition and plant layout, and their purpose was subsistence, commercial reasons, or both. The research article provides the methodology (e.g., communication plan, plant choice, metrics, etc.) of a farmer participant-based study and shares many specific insights that could help inform future farmer participant-based projects. A highlighted point was that their objectives would determine the design-smaller family scale could increase the plant diversity significantly, whereas a larger commercial scale required fewer species that were easier to manage, harvest and had a greater societal value. The participants acknowledged that the high diversity of plants was the main challenge of managing the system, as well as recognizing that if FGSs were to be scaled up there would need to be more human involvement (i.e., customer you-picks, paid labour) or continued dependency on robots, which predominantly require fossil fuels to operate with growing possibilities for solar-operated options. A major benefit noted was that the edible forest gardens were "beautiful places that attracted both humans and beneficial insects". They concluded that while the FGSs grew abundant food rich in minerals there was a lack of management techniques rooted in local ecologies and limited data on the amount that plants yield, which is a primary consideration when designing a food system. This issue is being addressed by Lovell et al. as well as multiple other studies which they reference [7].

Complimentary to the above, the largest and most recent review of alley cropping literature provides a comprehensive inventory of the species and techniques used in agroforestry in temperate regions [57]. They recommend that future work in agroforestry include four "frontiers": (1) increasing the diversity of tree species within systems (i.e., currently $74 \%$ of observed studies have only a single tree species); (2) recognizing tree crop potential for food and fodder (i.e., only $24 \%$ of alley cropping systems used trees for food and fodder); (3) replacing annual plants with perennials in the alley ways of tree rows (around the world, $66 \%$ of alleys are planted to annuals, compared to $13 \%$ herbaceous plants and 22\% woody perennials); and (4) "trees for crop facilitation": spreading awareness and practice of nitrogen-fixing trees (e.g., black locust (Robinia pseudoacacia L.) and alder (Alnus spp. Mill.)), utilizing crops that grow with some shade, and mulch generation in alleys. The vast amount of research 
compiled in this review alongside the focused four areas of recommended research can help guide future trials to increase the effectiveness of agroforestry goals. This includes expanding the application of agroforestry beyond the stereotypical "marginal land", to all land.

The momentum created by these studies, along with the specific information and process guides, opens opportunities for academics to cooperate with community growers in future trials to move FGSs forward in transforming agriculture.

\section{Future Work}

Development of temperate climate forest garden systems is occurring at an increasing rate with community groups growing to meet their needs, commercial growers transitioning their practices, and academics producing a recent surge of momentous research. Academic institutions have access to the tools, information, funding, and processes to support the creation of long-term trials in relation with growers who prioritize local communities. If we want to fully transform monoculture agriculture and connected societal culture, it is important to continue to actively acknowledge and challenge the impacts of these cultures on people and the land. Continuing to address the intersecting societal patterns of imperialism, capitalism, white privilege, and patriarchy which contribute to climate change, species extinction, land degradation and other major issues will be challenging, especially for the Indigenous communities. This is why it is important for academics to continue to build relationships with Indigenous groups working for food sovereignty and to adopt frameworks of Indigenous solidarity, permaculture, and agroecology so that practices are guided by principles that care for people and the land.

Suggested next steps for academic institutions based in their unique contexts are: (1) Form a committee to learn (with contributions from Indigenous food sovereignty groups) about how imperialism, capitalism, white privilege, and patriarchy influence structure (organizational, funding, educational, research, etc.) and actions in food systems; (2) Make a plan with specific steps and timelines to implement changes in structure and actions based on the committee's findings; (3) Expand learning and changes into existing research projects, outreach networks, collaborating organizations, and sources of funding. Prioritize projects, networks, organizations, and funding sources that are led by Indigenous groups working for food sovereignty; (4) Build relationships with community groups growing food systems that incorporate diverse perennial plants and apply principles that value people and the land; (5) Propose to support them in developing long-term trials in forest garden systems to see how incorporating diverse perennial plants impacts social, environmental, and economic metrics. Use the tools, frameworks, guides, information, and lessons shared in this review to create the template of research.

The recommended next steps within long-term FGS trials include: (1) Replicating long-term FGS trials on larger scales to provide models to increase adoption by commercial growers; (2) More research on the management, harvest techniques, plant yields, and marketing of food systems with diverse perennial plants; (3) Finding equitable and ethical responses to need for increased human labour work force and or transition from fossil fuels for robot labour; (4) More research and sharing of regional ecology-based practices for food system design; (5) Expanding agroforestry practices to all agricultural land, not confining it to "marginal" land; (6) Increasing diversity of tree species within rows of trees in alley cropping systems; (7) Researching perennial crops instead of annual crops in alleys between tree rows; (8) Determining capacity of perennial plants for food and fodder; (9) Researching how temperate climate trees might facilitate other plants, such as nitrogen-fixing trees and perennial plants that yield usable items in the shade.

We know the impacts of monoculture agriculture and we have growing momentum in perennial-based food systems. In partnership with Indigenous food sovereignty efforts and community growers, academics can help to develop practical processes to transition our food systems so that people, land, and water are prioritized. 
"The market economy story has spread like wildfire, with uneven results for human well-being and devastation for the natural world. But it is just a story we have told ourselves and we are free to tell another, to reclaim the old one. One of these stories sustains the living systems on which we depend. One of these stories opens the way to living in gratitude and amazement at the richness and generosity of the world. One of these stories asks us to bestow our own gifts in kind, to celebrate our kinship with the world. We can choose. If all the world is a commodity, how poor we grow. When all the world is a gift in motion, how wealthy we become".--Robin Wall Kimmerer [58].

Author Contributions: The following work was completed by the respective contributing authors: Writing-Original Draft Preparation, P.W.; Writing-Review \& Editing, P.W., R.V.A., R.C.M; Supervision, R.V.A., R.C.M; and, Funding Acquisition, R.V.A., R.C.M.

Funding: This research was partially funded by a Loblaw Co. Ltd. operating grant to RC Martin This research was partially funded by a Loblaw Co. Ltd. operating grant to RC Martin.

Acknowledgments: I acknowledge that this research was carried out on Indigenous Attawandaron traditional territory and offer my respect to the Indigenous peoples of this area.

Conflicts of Interest: The authors declare no conflict of interest.

\section{References}

1. Ontario: Forest regions. Available online: https://www.ontario.ca/environment-and-energy/forest-regions (accessed on 15 May 2014).

2. Graves, M.; Deen, B.; Fraser, E.; Martin, R. Chapter 6-Practical response: Options for agriculture. In Planning for Rural Resilience: Coping with Climate Change and Changing Energy Futures; Wayne, J.C., Ed.; University of Manitoba Press: Winnipeg, MB, Canada, 2015; ISBN 0887557805.

3. Tomich, T.P.; Brodt, S.; Ferris, H.; Galt, R.; Horwath, W.R.; Kebreab, E.; Leveau, J.H.; Liptzin, D.; Lubell, M.; Merel, P.; et al. Agroecology: A review from a global-change perspective. Annu. Rev. Environ. Resour. 2011, 36, 193-222. [CrossRef]

4. Jacke, D.; Toensmeier, E. Edible Forest Gardens, Volume 1; Chelsea Green: White River Junction, VT, USA, 2005.

5. Wiersum, K.F. Forest gardens as an 'intermediate' land-use system in the nature-culture continuum: Characteristics and future potential. Agrofor. Syst. 2004, 61, 123-134.

6. Uprety, Y.; Asselin, H.; Dhakal, A.; Julien, N. Traditional use of medicinal plants in the boreal forest of Canada: Review and perspectives. J. Ethnobiol. Ethnomed. 2012, 8, 7. [CrossRef] [PubMed]

7. Lovell, S.T.; Dupraz, C.; Gold, M.; Jose, S.; Revord, R.; Stanek, E.; Wolz, K.J. Temperate agroforestry research: Considering multifunctional woody polycultures and the design of long-term field trials. Agrofor. Syst. 2017, 1-19. [CrossRef]

8. Jose, S. Agroforestry for ecosystem services and environmental benefits: An overview. Agrofor. Syst. 2009, 76, 1-10. [CrossRef]

9. Nerlich, K.; Graeff-Honninger, S.; Claupeinm, W. Agroforestry in Europe: A review of the disappearance of traditional systems and development of modern agroforestry practices, with emphasis on experiences in Germany. Agrofor. Syst. 2013, 87, 475-492. [CrossRef]

10. Thevathasan, N.V.; Gordon, A.M. Ecology of tree intercropping sysetms in the North temperate region: Experiences from Southern Ontario. Agrofor. Syst. 2004, 61, 257-268.

11. Indian Act. Available online: http:/ / laws-lois.justice.gc.ca/eng/acts/i-5/ (accessed on 10 April 2018).

12. Special Rapporteur on the Right to Food: Mission to Canada. Available online: https:// foodsecurecanada. org/sites/foodsecurecanada.org/files/20120321_SRRTF_Aide-m\%C3\%A9moire_Canada.pdf (accessed on 15 April 2018).

13. Valdivia, C.; Barbieri, C.; Gold, M.A. Between forestry and farming: Policy and environmental implications of the barriers to agroforestry adoption. Can. J. Agric. Econ. 2012, 60, 155-175. [CrossRef]

14. Country Pasture and Forage Resource Profile: Canada. Available online: http://www.fao.org/ag/agp/ AGPC/doc/Counprof/Canada/Canada.html (accessed on 20 February 2014).

15. Anishinabek Nation. Available online: www.anishinabek.ca (accessed on 2 March 2018).

16. Odawa. Available online: www.firstnationsseeker.ca/Ottawa.html (accessed on 2 March 2018). 
17. Haudenosaunee Confederacy of Grand River. Available online: www.haudenosauneeconfederacy.com/ (accessed on 2 March 2018).

18. Nation Huronne Wendat. Available online: www.wendake.ca (accessed on 2 March 2018).

19. Native Land Territory Maps. Available online: www.native-land.ca (accessed on 2 March 2018).

20. Simpson, L.R. Anticolonial strategies for the recovery and maintenance of Indigenous knowledge. Am. Indian Q. 2004, 28, 373-384. [CrossRef]

21. Treaty Texts-Treaty No. 3. Available online: www.aadnc-aandc.gc.ca/eng/1100100028675/1100100028679 (accessed on 10 March 2018).

22. History of Loblaw Companies Limited. Available online: www.referenceforbusiness.com/history2/27/ Loblaw-Companies-Limited.html (accessed on 10 March 2018).

23. Faculty Directory. Available online: www.aadnc-aandc.gc.ca/eng/1100100028675/1100100028679 (accessed on 10 March 2018).

24. Review: Reclaiming Our Native Spirit and Identity. Available online: http:/ /www.oralhistoryforum.ca/ index.php/ohf/article/viewFile/43/68 (accessed on 20 March 2018).

25. Changes in the Landscape of Southern Ontario, Canada since 1750: Impacts of European Colonization. Available online: http://projects.upei.ca/climate/publications/books-on-climate/integrated-mappingassessment-2005/ (accessed on 10 March 2014).

26. Kimmins, J.P. Forest Ecology: A Foundation for Sustainable Forest Management and Environmental Ethic in Forestry, 3rd ed.; Prentice Hall: Upper Saddle River, NJ, USA, 2004.

27. Statistical Summary of Ontario Agriculture. Available online: http://www.omafra.gov.on.ca/english/stats/ agriculture_summary.htm\#farm (accessed on 20 June 2014).

28. Truth and Reconciliation Commission of Canada Reports and Findings. Available online: www.trc.ca/ websites/trcinstitution/index.php?p=905 (accessed on 20 March 2018).

29. Altieri, M.A.; Nicholls, C.I. Agroecology scaling up for food sovereignty and resiliency. Sustain. Agric. Rev. 2012, 11. [CrossRef]

30. Van Acker, R.C. Sustainable agriculture development requires a shift from an industrial to a multifunctional model. Int. J. Agric. Sustain. 2008, 6, 1-2. [CrossRef]

31. Indigenous Food Sovereignty. Available online: https://foodsecurecanada.org/sites/foodsecurecanada. org/files/DP1_Indigenous_Food_Sovereignty.pdf (accessed on 25 March 2018).

32. Hillel, D. Out of the Earth: Civilization and the Life of the Soil; University of California Press: Berkeley, CA, USA, 1991.

33. Working Group on Indigenous Food Sovereignty. Available online: www.indigenousfoodsystems.org/about (accessed on 20 March 2018).

34. Ferguson, R.S.; Lovell, S.T. Permaculture for agroecology: Design, movement, practice and worldview. A review. Agron. Sustain. Dev. 2014, 34, 251-274. [CrossRef]

35. Mollison, B. Permaculture: A Designer's Manual; Tagari Publications: Tasmania, Australia, 1988.

36. Hart, R. Forest Gardening: Cultivating an Edible Landscape, 2nd ed.; Chelsea Green: White River Junction, VT, USA, 1996.

37. Smith, J.R. Tree Crops: A Permanent Agriculture; Island Press: Washington, DC, USA, 1987.

38. Crawford, M.; Cambridge, UK. Personal communication, 2014.

39. Crawford, M. Creating a Forest Garden: Working with Nature to Grow Edible Crops; UIT Cambridge Ltd.: Cambridge, UK, 2010.

40. Agroforestry News. Available online: www.agroforestry.co.uk.agnews.html (accessed on 14 June 2014).

41. Remiarz, T. Forest Gardening in Practice; Permanent Publications: Hampshire, UK, 2017; ISBN 978-1-85623-293-7.

42. Badgersett Research Corporation: Woody Agriculture Research and Development. Available online: www. badgersett.com (accessed on 24 June 2014).

43. Redesigning Agriculture in Nature's Image. Available online: www.forestag.com (accessed on 24 June 2014).

44. Forest Garden Workshops. Available online: www.saugeenfirstnation.ca/news_item/php?ItemID=461 (accessed on 1 March 2018).

45. Carolinian Food Forest. Available online: www.wildcraftpermaculture.ca/index.php/projects (accessed on 1 March 2018). 
46. The Chippewa Sustainable Living Project. Available online: www.wearebuildingbetter.com/chippewasustainable-living-site/ (accessed on 1 March 2018).

47. Forest Gardening Regenerative Design. Available online: www.thelivingcentre.com/programs/forestgardening (accessed on 1 March 2018).

48. Guelph Community Food Forest. Available online: www.guelphcommunityfoodforest.org (accessed on 5 March 2018).

49. Agriculture and Agri-Food Canada. Available online: http://www.agr.gc.ca/eng/home/?id=1395690825741 (accessed on 5 March 2018).

50. Ministry of Agriculture, Food, and Rural Affairs. Available online: www.omafra/gov.on.ca/ (accessed on 5 March 2018).

51. Food Sovereignty Assessment Tool. Available online: www.indigenousfoodsystems.org/sites/default/files/ tools / FNDIFSATFinal.pdf (accessed on 5 March 2018).

52. Unsettling Settler Food Movements: Food Sovereignty and Decolonization in Canada. Available online: https: / / www.erudit.org/en/journals / cuizine/2016-v7-n2-cuizine02881/1038478ar/ (accessed on 28 May 2018).

53. Woody Perennial Polyculture Research Site. Available online: https://icap.sustainability.illinois.edu/ project/woody-perennial-polyculture-wpp-research-site (accessed on 20 June 2015).

54. Laying the Groundwork for Widespread Agroforestry in the Midwest. Available online: www. savannainstitute.org (accessed on 20 June 2015).

55. Farmer led Research-Ecological Farmers of Ontario. Available online: www.efao.ca/farmer-led-research (accessed on 20 March 2018).

56. Björklund, J.; Eksvärd, K.; Schaffer, C. Exploring the potential of edible forest gardens: Experiences from a participatory action research project in Sweden. Agrofor. Syst. 2018. [CrossRef]

57. Wolz, K.J.; DeLucia, E.H. Alley cropping: Global patterns of species composition and function. Agric. Ecosyst. Environ. 2018, 252, 61-68. [CrossRef]

58. Kimmerer, R. Braiding Sweetgrass; Milkweed Editions: Minneapolis, MN, USA, 2014.

(C) 2018 by the authors. Licensee MDPI, Basel, Switzerland. This article is an open access article distributed under the terms and conditions of the Creative Commons Attribution (CC BY) license (http:/ / creativecommons.org/licenses/by/4.0/). 